\title{
Sensitized mechanoluminescence design toward mechanically induced intense red emission from transparent polymer films
}

\author{
Citation for published version (APA): \\ Yang, F., Yuan, Y., Sijbesma, R. P., \& Chen, Y. (2020). Sensitized mechanoluminescence design toward \\ mechanically induced intense red emission from transparent polymer films. Macromolecules, 53(3), 905-912. \\ https://doi.org/10.1021/acs.macromol.9b02221
}

\section{Document license: \\ TAVERNE}

DOI:

10.1021/acs.macromol.9b02221

Document status and date:

Published: 11/02/2020

\section{Document Version:}

Publisher's PDF, also known as Version of Record (includes final page, issue and volume numbers)

\section{Please check the document version of this publication:}

- A submitted manuscript is the version of the article upon submission and before peer-review. There can be important differences between the submitted version and the official published version of record. People interested in the research are advised to contact the author for the final version of the publication, or visit the DOI to the publisher's website.

- The final author version and the galley proof are versions of the publication after peer review.

- The final published version features the final layout of the paper including the volume, issue and page numbers.

Link to publication

\footnotetext{
General rights

- You may freely distribute the URL identifying the publication in the public portal. follow below link for the End User Agreement:

www.tue.nl/taverne

\section{Take down policy}

If you believe that this document breaches copyright please contact us at:

openaccess@tue.nl

providing details and we will investigate your claim.
}

Copyright and moral rights for the publications made accessible in the public portal are retained by the authors and/or other copyright owners and it is a condition of accessing publications that users recognise and abide by the legal requirements associated with these rights.

- Users may download and print one copy of any publication from the public portal for the purpose of private study or research.

- You may not further distribute the material or use it for any profit-making activity or commercial gain

If the publication is distributed under the terms of Article $25 \mathrm{fa}$ of the Dutch Copyright Act, indicated by the "Taverne" license above, please 


\title{
Sensitized Mechanoluminescence Design toward Mechanically Induced Intense Red Emission from Transparent Polymer Films
}

\author{
Fan Yang," Yuan Yuan," Rint P. Sijbesma,* and Yulan Chen*
}

Cite This: Macromolecules 2020, 53, 905-912

Read Online

ABSTRACT: Mechanoresponsive polymers with intense red emission are highly desirable in view of the strong penetrability and high resolution of red luminescence. Herein we introduce the sensitized luminescence of rare-earth $\mathrm{Eu}$ (III) complexes into the mechanochemiluminescence from polymeric dioxetane in a covalent way. By controlling the energy-transfer process from mechanically broken dioxetane to the $\mathrm{Eu}(\mathrm{III})$ center, bright red emission from transparent poly(methyl acrylate) films was achieved for the first time. Importantly, mechanoluminescence sensitivity is greatly improved, enabling the location and timing of

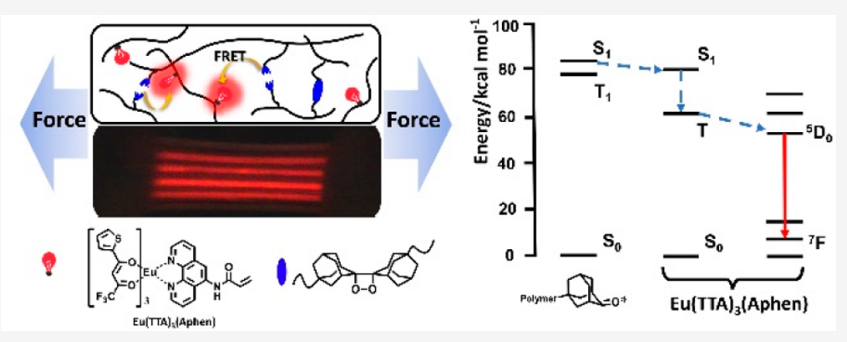
bond scission with high resolution. A sensitive stretchable device with the polymer film as an emissive layer was fabricated by a facile surface-engineering method, which can emit patterned red light upon deformation. This sensitized mechanoluminescence design thus expands the useful space of luminescent stress probes.

\section{INTRODUCTION}

Red-emissive materials have attracted much attention for their potential applications in sensors, bioimaging, and lightemitting diodes with advantages of low energy, strong penetrability, and high resolution. ${ }^{1-3}$ Europium(III) (Eu(III)) complexes, with their luminescent $4 \mathrm{f} \rightarrow$ ff transitions leading to the emission of narrow bands of red light, have been widely used as luminescent probes in biosensing, optical devices, and laser materials. Because of their predominant photophysical properties, such as intense red emission, excellent monochromaticity, and a large Stokes shift, various $\mathrm{Eu}(\mathrm{III})$ containing polymers have been developed, which can emit red light by activation with, for example, UV light and electricity. $^{4-10}$

The significance of optically functional polymers is strongly tied to the rapid growth of electronic and material industries, which, in turn, have created a great demand for transparent and durable polymers. However, the failure of polymeric materials is an unavoidable yet complex phenomenon that finds its origin in chemical events on the molecular scale. Although the failure mechanisms of different polymers have been studied in detail, many aspects are incompletely understood, especially the specific molecular details regarding the failure initiation state. What is already known is that the stress-induced scission of chemical bonds often plays a critical role in the initiation of failure; therefore, knowing the precise location and timing of chain-scission events is key to unravelling failure mechanisms. Recent years have witnessed a growing interest in mechanoresponsive polymers that can convert mechanical force into optical signals, including color changes, ${ }^{11-13}$ fluorescence, ${ }^{14-18}$ and chemiluminescence. ${ }^{19-22}$
These smart materials, serving as versatile spectroscopic sensors, were used to investigate specific molecular failure events and macroscopic properties of polymers. ${ }^{23,24}$ Mechanochemiluminescent polymers are particularly attractive because they probe mechanochemical chain scission with high spatial and temporal resolution and have the capability of providing exceptionally detailed insight into the origins and mechanisms of failure in polymers. ${ }^{21}$ The first work on mechanochemiluminescent polymers was reported by us in 2012. ${ }^{19}$ When the four-membered bis(adamantyl)-1,2-dioxetane ring was covalently incorporated into polymer backbones, it decomposed into two ketone moieties under mechanical force. One of these moieties was in the excited state and relaxed to the ground state with concomitant blue light $\left(\lambda_{\mathrm{em}}=\right.$ $420 \mathrm{~nm}$ ).

To further improve the sensitivity of this autoluminescent stress probe, fluorescent dyes were incorporated in polymer films as energy acceptors, leading to mechanochemiluminescent polymers with appreciable green or yellow emission. ${ }^{19,22,25}$ However, the intense absorption of conjugated dyes deepened the color of the films, which severely limited their applications. In particular, because of their limited energytransfer efficiency, red-emissive mechanoresponsive polymers have rarely been explored, although on account of the strong penetrability and high resolution of red light, such systems are

Received: October 21, 2019

Revised: January 11, 2020

Published: February 3, 2020 
(a)

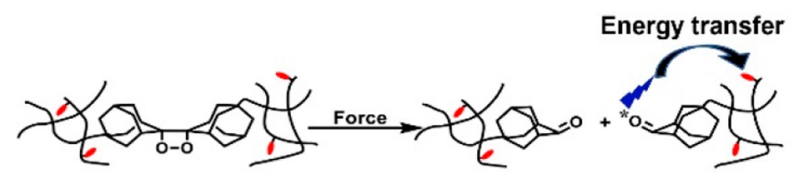

(b)

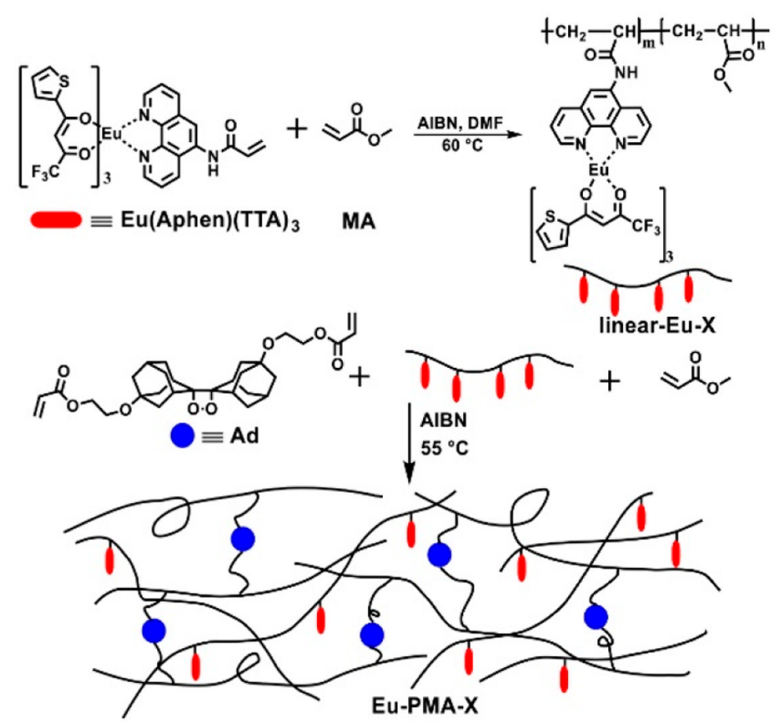

(c)

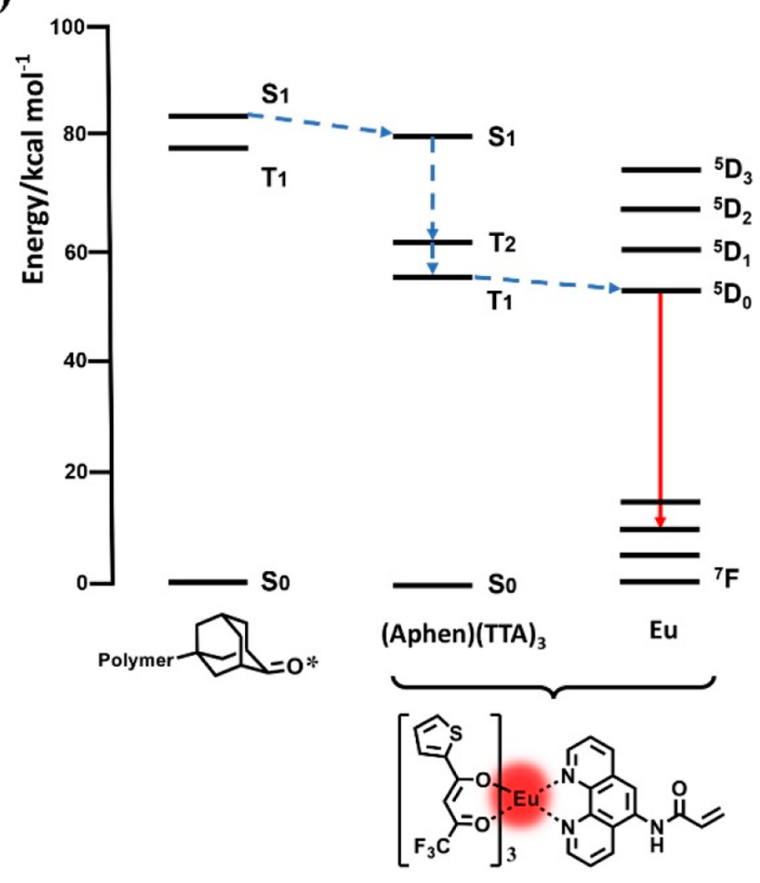

Figure 1. (a) Schematic representation of mechanically induced chemiluminescence from bis(adamantyl)-1,2-dioxetane cross-linked film (EuPMA-X) through energy transfer. (b) Synthetic scheme of Eu-PMA-X. (c) Jablonski diagram depicting the pathway for energy transfer from the excited ketone of dioxetane cleavage to $\mathrm{Eu}(\mathrm{III}) .^{28,29}$

potentially useful for sensitively mapping mechanical force. We expect that more fundamental insight into mechanotransduction and failure mechanisms within soft materials would benefit enormously from the availability of mechanochemiluminescent transparent polymer films that can emit intense red light.

Our motivation was to seek structural modifications of the dioxetane force probe, which would allow the location and timing of bond scission with improved resolution. We herein bring forth a sensitized mechanoluminescence design; that is, without sacrificing the stability of the dioxetane probe, redlight mechanochemiluminescent poly(methyl acrylate) (PMA) films with the $\mathrm{Eu}(\mathrm{III})$ complex as the side groups and 1,2dioxetane as the cross-linker were developed. The sensitized luminescence from the $\mathrm{Eu}(\mathrm{III})$ complex promoted an energytransfer process across the polymer network, and thus bright red emission from strained transparent films was realized for the first time (Figure 1a). Taking advantage of the transparency of the films and their high mechanoluminescence sensitivity, we further demonstrated that such mechanically induced red light can be patterned using a simple bilayer system. In terms of the emission wavelength, light intensity, and transparency, improvement in the detection of bond scission and stress mapping in polymer films and flexible devices can thus be achieved. The present work thus not is only an essential complemental case for stimuli-responsive redemissive materials but also represents the improvement of the stress probe regarding its autoluminescence feature. ${ }^{26,27}$

\section{EXPERIMENTAL SECTION}

Synthesis of Eu-Containing Linear PMA (linear-Eu-X). The linear-Eu-Xs were synthesized according to the literature. ${ }^{30,31}$ Under an argon atmosphere, methyl acrylate $(1.0 \mathrm{~mL}, 11.035 \mathrm{mmol})$, $\mathrm{Eu}$ (TTA) ${ }_{3}$ (Aphen), AIBN (10 mg), and dimethylformamide (DMF) solvent $(6 \mathrm{~mL})$ were mixed and added to a glass polymerization tube.
The polymerization was carried out by heating the sealed tube in an oil bath to $60{ }^{\circ} \mathrm{C}$ for $60 \mathrm{~h}$. The viscous homogeneous solution was then dissolved in tetrahydrofuran (THF) and poured into $200 \mathrm{~mL}$ of methanol with stirring. The resulting precipitate was redissolved in THF and purified by the reprecipitation of the solution with methanol twice and finally dried under vacuum at $50{ }^{\circ} \mathrm{C}$ for $24 \mathrm{~h}$. Linear PMA without a europium complex (linear-Eu-0) was prepared using the same polymerization conditions for comparison.

Synthesis of Eu-Containing Cross-Linked PMA (Eu-PMA-X). In a glass vial, methyl acrylate $(2.0 \mathrm{~mL})$, linear-Eu-X $(0.3 \mathrm{~g})$, Ad (10 $\mathrm{mg})$, AIBN $(10 \mathrm{mg})$, and solvent THF $(1.0 \mathrm{~mL})$ were mixed until fully dissolved. The solution was put into a Teflon mold $(30 \times 50 \times$ $10 \mathrm{~mm}$ ), covered with a glass plate, and placed in a glovebox. Then, the solution was heated to $55^{\circ} \mathrm{C}$ for $12 \mathrm{~h}$. The resulting polymer film was dried under vacuum at $60^{\circ} \mathrm{C}$ for $12 \mathrm{~h}$. Finally, the film was taken out and cut into rectangles of $5.3 \times 25 \mathrm{~mm}$ for further testing. The average thickness of the films was $0.25 \pm 0.05 \mathrm{~mm}$.

\section{RESULTS AND DISCUSSION}

The $\mathrm{Eu}(\mathrm{III})$ complex, Eu(TTA) ${ }_{3}$ (Aphen), employed as a polymerizable energy acceptor, was synthesized according to the literature. ${ }^{28}$ Herein the unsymmetrical ligands, 1,10phenanthroline (Aphen) and 2-thenoyltrifluoroacetone (TTA), served as the antennae to harvest blue light from the excited-state adamantanone and sensitized the red emission from the $\mathrm{Eu}(\mathrm{III})$ center. As depicted in Figure $1 \mathrm{~b}$, the $\mathrm{Eu}(\mathrm{III})$ containing cross-linked PMA (Eu-PMA-X) films were prepared by a two-step free radical polymerization. First, the $\mathrm{Eu}(\mathrm{III})$-containing linear PMAs (linear-Eu-X) with varying amounts of Eu(III) complex were synthesized by the thermally induced copolymerization of $\mathrm{Eu}(\mathrm{TTA})_{3}$ (Aphen) and methyl acrylate (MA) with AIBN as an initiator. The purpose of this step was not only to ensure the covalent incorporation of $\mathrm{Eu}$ (III) acceptor into PMA chains but also to avoid luminescence quenching derived from ionic aggregates of 
$\mathrm{Eu}(\mathrm{III}) .^{32}$ The feed ratios and molecular weights of linear-Eu$\mathbf{X}$ are shown in Table 1 . The linear-Eu-2 was analyzed by gel

Table 1. Feed Ratios and Molecular Weights of linear-Eu-X

\begin{tabular}{ccccc} 
& $\begin{array}{c}\text { MA } \\
\text { (equiv) }\end{array}$ & $\begin{array}{c}\text { Eu(TTA) } \\
(\text { equiv })\end{array}$ & $\begin{array}{c}M_{\mathrm{n}} \\
(\mathrm{kDa})\end{array}$ & PDI \\
linear-Eu-0 & 100 & 0.00 & 19 & 1.53 \\
linear-Eu-1 & 100 & 0.25 & 19 & 1.93 \\
linear-Eu-2 & 100 & 0.42 & 22 & 1.84 \\
linear-Eu-3 & 100 & 0.85 & 20 & 1.81 \\
\hline
\end{tabular}

permeation chromatography (GPC) with both UV (monitored at $342 \mathrm{~nm}$ ) and RI detectors (Figure S2). The peaks recorded by the two detectors are in good agreement with each other. The calculated concentrations of the complex in polymers are consistent with the feed ratios (Figure S3). These results showed that the $\mathrm{Eu}(\mathrm{III})$ complex has been well incorporated into the prepared PMA polymer. The FT-IR spectrum of linear-Eu-2 confirmed that its structure was similar to that of PMA. The $\mathrm{C}=\mathrm{C}$ stretching vibration of $\mathrm{Eu}(\mathrm{TTA})_{3}$ (Aphen) $\left(1624 \mathrm{~cm}^{-1}\right)$ was absent in linear-Eu-2, indicating a completion of polymerization (Figure S4), and new absorption peaks at 1603,1535 , and $1305 \mathrm{~cm}^{-1}$ ascribed to the $\mathrm{C}=\mathrm{O}$, $\mathrm{C}=\mathrm{C}$, and $\mathrm{C}-\mathrm{F}$ stretching vibrations of the ligand (TTA), respectively, supported the successful incorporation of the complex into the linear polymer. The structure of Eu(III)containing linear PMA was also verified by the ${ }^{1} \mathrm{H}$ NMR spectrum (Figure S5), in which the proton peaks assigned to the terminal vinyl group attached on $\mathrm{Eu}(\mathrm{TTA})_{3}$ (Aphen) and MA have completely disappeared and all of the peaks become broad. $^{29}$ Then, the Eu-PMA-X films were synthesized by crosslinking linear-Eu-X with bisacrylate-functionalized bis(adamantyl)-1,2-dioxetane (Ad) as a cross-linker. Glasstransition temperatures $\left(T_{\mathrm{g}}\right)$ of all of the linear-Eu-X and Eu-PMA-X samples were in the range of $13-21{ }^{\circ} \mathrm{C}$, as determined by differential scanning calorimetry (DSC) analysis (Figure S6), which supported the notion that all of these materials were elastic at room temperature. A slight increase in $T_{\mathrm{g}}$ from linear-Eu-X to Eu-PMA-X samples could be ascribed to the cross-linking-induced constraints of polymer chains. ${ }^{33}$

In contrast with previous reports using colored dyes as acceptors, the Eu-PMA-X films are transparent. The transparency of the films with different amounts of $\mathrm{Eu}$ (III) is illustrated in Figure 2. The ratios of light transmittance of EuPMA-X films to blank film Eu-PMA-0 are between 90 and 99\% in the visible region, and the Eu-PMA-X films on the labeled paper are colorless. The results demonstrate that the introduction of $\mathrm{Eu}(\mathrm{TTA})_{3}$ (Aphen) has little effect on the optical properties of the polymer films in the visible region. Notably, good transparency and colorless are critical, concerning the elimination of background interference and good light penetration through the film interior, which is particularly important for improving the sensitivity of damage probing in thick films and for expanding the useful space of mechanoluminescence.

The excitation and emission spectra of the Eu-PMA-X films were measured (Figure S7). The excitation band occurred in the range of $320-420 \mathrm{~nm}$, which could be attributed to the $\pi-\pi^{*}$ transitions of the ligands, and exhibited good overlapping with the thermochemiluminescence spectrum of bis(adamantyl)-1,2-dioxetane. ${ }^{34}$ This result indicates that if bis(adamantyl)-1,2-dioxetane is broken into an excited

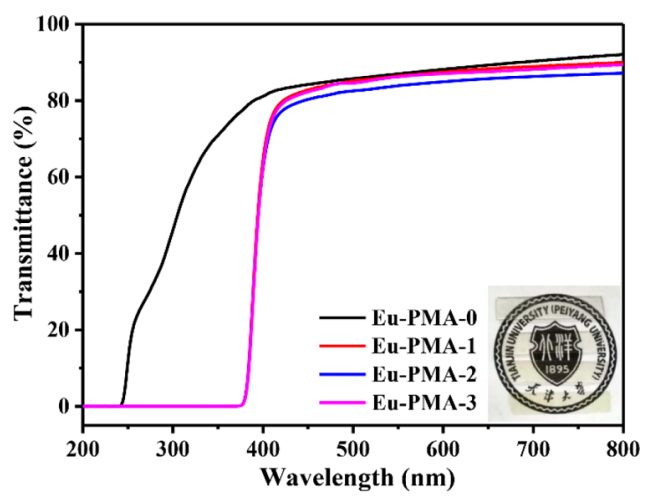

Figure 2. Representative UV-vis transmittance curves of Eu-PMA-X films. The inset shows four pieces of films on a labeled paper (film thickness: $0.24 \mathrm{~mm}$ for Eu-PMA-0, $0.27 \mathrm{~mm}$ for Eu-PMA-1, $0.29 \mathrm{~mm}$ for Eu-PMA-2, and $0.26 \mathrm{~mm}$ for Eu-PMA-3). The Tianjin University logo is used with permission from Tianjin University.

adamantanone, and its emissive light can be absorbed by the Eu-PMA-X film, which is the prerequisite for the energytransfer process, which thus suggests the possibility of energy transfer from the broken bis(adamantyl)-1,2-dioxetane to the $\mathrm{Eu}(\mathrm{TTA})_{3}$ (Aphen) moiety. Because of the sensitizing effect from the ligand absorption and the intramolecular energy transfer from ligands to $\mathrm{Eu}(\mathrm{III})$ ions, the Eu-PMA-X films exhibited intense red emission under $420 \mathrm{~nm}$ excitation, with a sharp emission band at $613 \mathrm{~nm}$, corresponding to the ${ }^{5} \mathrm{D}_{0} \rightarrow$ ${ }^{7} \mathrm{~F}_{2}$ transition of $\mathrm{Eu}(\mathrm{III})$ ions. Other characteristic narrow peaks at 591, 651, and $699 \mathrm{~nm}$, assigned to the ${ }^{5} \mathrm{D}_{0} \rightarrow{ }^{7} \mathrm{~F}_{1},{ }^{5} \mathrm{D}_{0}$ $\rightarrow{ }^{7} \mathrm{~F}_{3}$, and ${ }^{5} \mathrm{D}_{0} \rightarrow{ }^{7} \mathrm{~F}_{4}$ transitions, respectively, were observed. ${ }^{4}$

The energy-transfer process within polymer films under mechanical force was also verified. Optomechanical tests of Eu-PMA-2 samples manifested bright-red luminescence upon deformation (Figure 3a). No light was detected with control PMA without 1,2-dioxetane. These results proved the mechanical nature of chemiluminescence from dioxetane, which can further undergo energy transfer to $\mathrm{Eu}(\mathrm{III})$ within the polymer network, leading to sensitized red light. The mechanoluminescence spectrum of the film exhibited four narrow emission peaks centered at 592,613,651, and $700 \mathrm{~nm}$, respectively (Figure $3 \mathrm{~b}$ and Figure $\mathrm{S} 8$ ). These peaks are assigned to the ${ }^{5} \mathrm{D}_{0} \rightarrow{ }^{7} \mathrm{~F}_{1},{ }^{5} \mathrm{D}_{0} \rightarrow{ }^{7} \mathrm{~F}_{2},{ }^{5} \mathrm{D}_{0} \rightarrow{ }^{7} \mathrm{~F}_{3}$, and ${ }^{5} \mathrm{D}_{0} \rightarrow$ ${ }^{7} \mathrm{~F}_{4}$ transitions, among which, the one from the ${ }^{5} \mathrm{D}_{0} \rightarrow{ }^{7} \mathrm{~F}_{2}$ electrodipole transition is the strongest, with a width at halfheight of $\sim 5 \mathrm{~nm}$. The very narrow band emission from the fractured film makes it reasonable that such a system could be used as a "monochromatic" light source for stress probing. The evolution of stress and light intensity versus strain during plastic deformation was derived from a representative video (Video S1 and Figure 3c). First, at low stress, weak luminescence throughout the polymer film was detected. Then, a steep increase in stress and the concentration of light emission was seen at the location of fracture immediately prior to failure. No further luminescence was observed after fracture. Intriguingly, the red mechanochemiluminescence was intense enough to be followed, even in the presence of weak extraneous light (Video S2). In contrast with mechanoluminescent red-emitting PMAs with physically mixed conjugated dyes, such as perylenediimide (PDI) and tetraphenylporphyrin (TPP) (Figure S9), the intrachain energy transfer and sensitized luminescence of Eu(III) in Eu-PMA-2 result in strongly enhanced light intensity with a narrow bandwidth. 
(a)

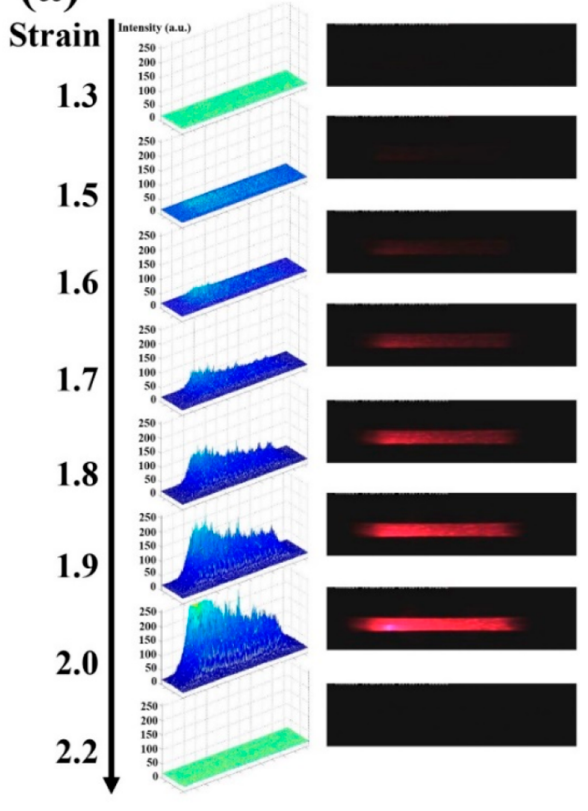

(b)

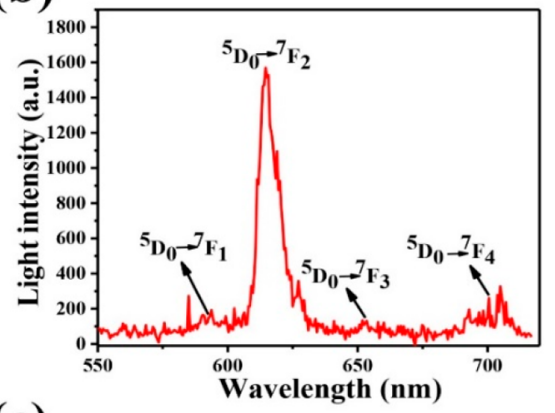

(c)

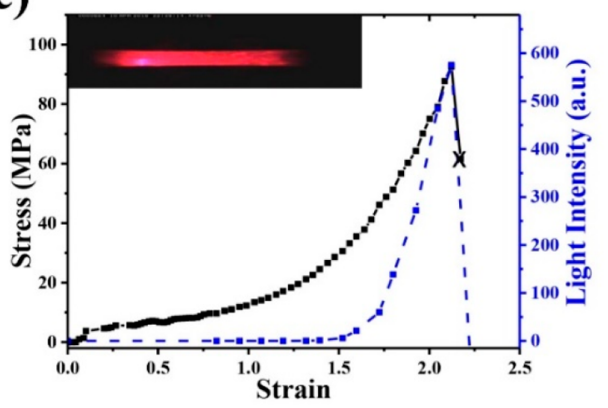

Figure 3. Stress and light intensity versus strain during stretching of a bulk film of Eu-PMA-2 at a strain rate of $20 \mathrm{~s}^{-1}$. (a) Optical images and intensity analysis of the stretched sample. (b) Luminescence spectrum of an Eu-PMA-2 film upon deformation. (c) Evolution of stress and light intensity versus strain. (The inset is a picture of Eu-PMA-2 emitting red light before fracture.) The analyzed intensity is based on the same region within the film.

(a)

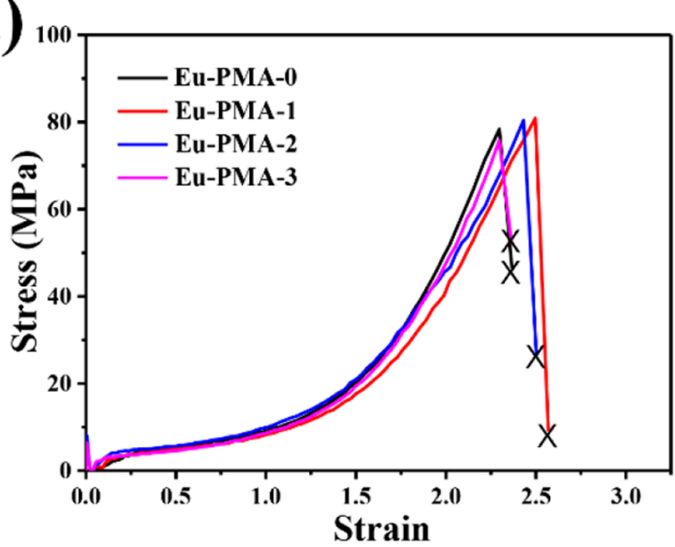

(c)

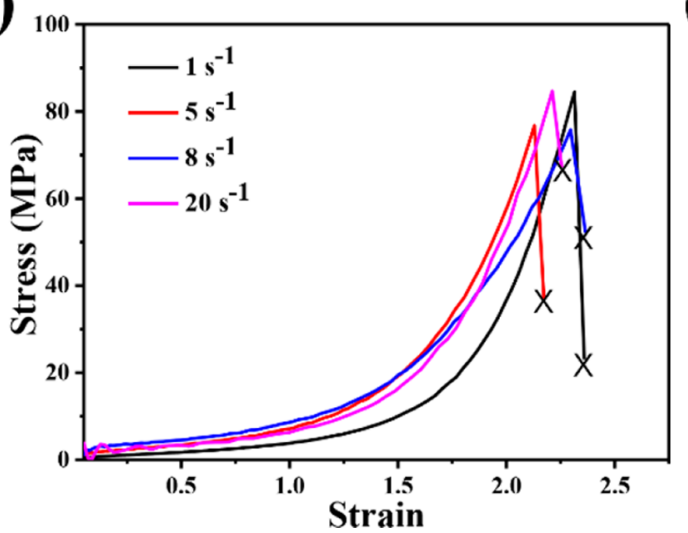

(b)

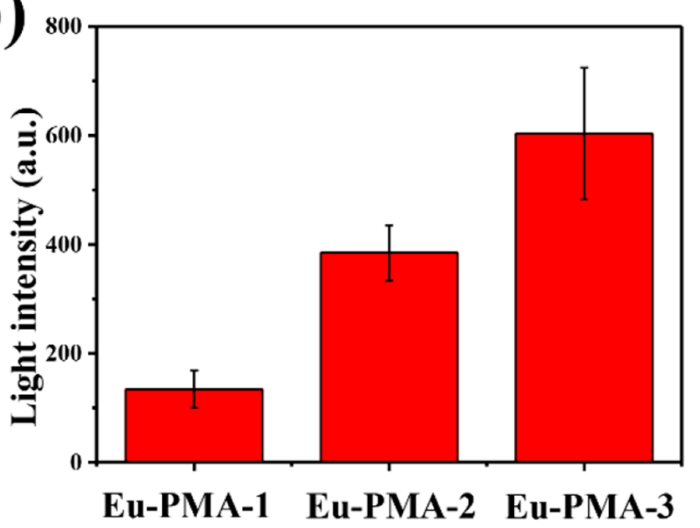

(d)

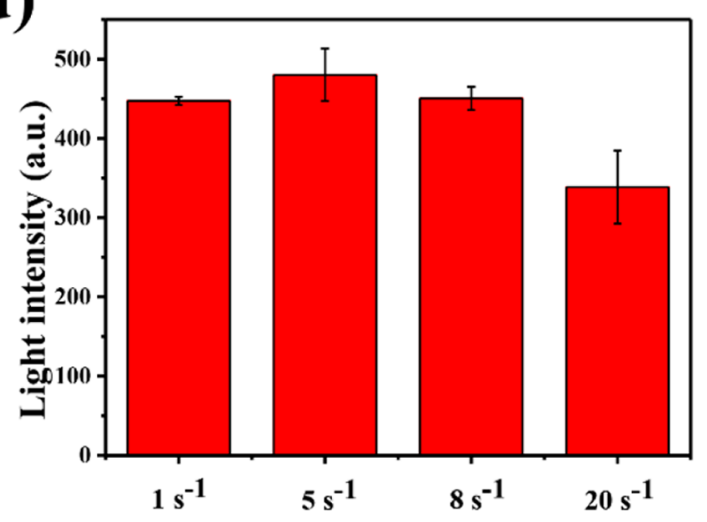

Figure 4. (a) Representative stress-strain curves of Eu-PMA-0, Eu-PMA-1, Eu-PMA-2, and Eu-PMA-3 at a strain rate of 8 s ${ }^{-1}$ and (b) the corresponding cumulative light intensity. (c) Stress-strain curves of Eu-PMA-2 at different strain rates and (d) the corresponding cumulative light intensity. Points for light intensity represent the average and standard deviations from three parallel experiments for each polymer. 
(a)

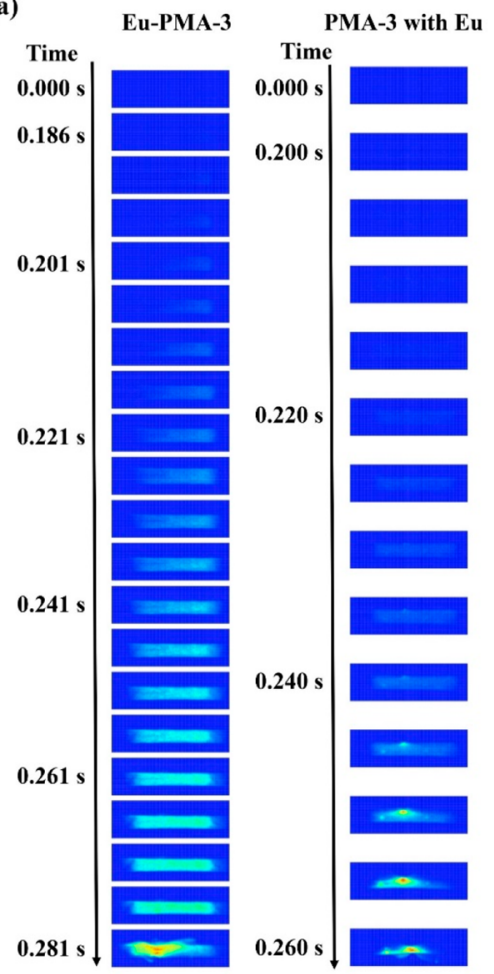

(b)

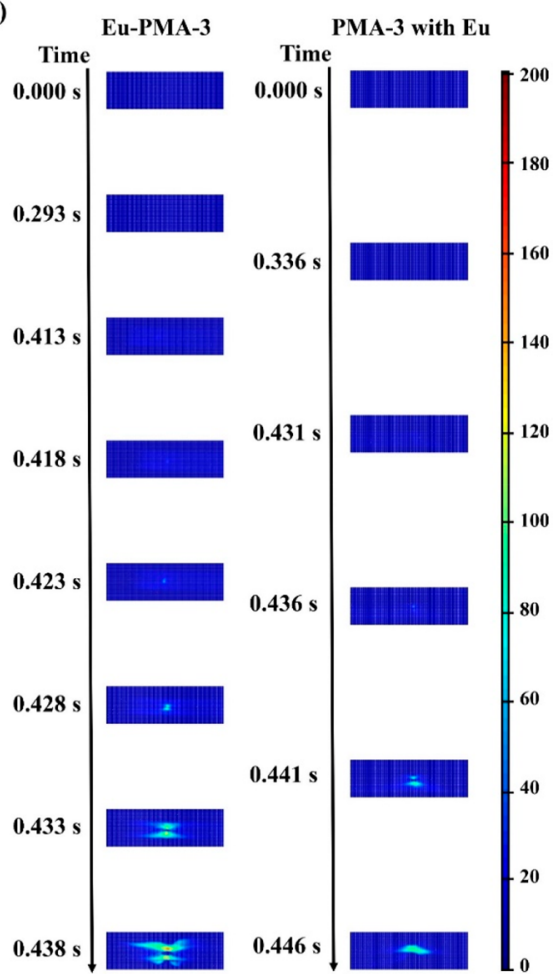

Figure 5. Mapping of bonds breakage providing more (a) temporal and (b) spatial information of mechanoluminescence from Eu-PMA-3 (left) compared with its physically mixed film (right). Light evolution is presented with $2 \mathrm{D}$ intensity-colorized images.

Furthermore, this strategy even works well with thick films because self-absorption from strongly colored dyes is avoided in the transparent films of Eu-PMA-2.

To shed more light on the optomechanical properties of these films, the effects of the Eu(III) concentration and the strain rates on the mechanoluminescence were studied. First, Eu-PMA-1, Eu-PMA-2, and Eu-PMA-3 films with varied $\mathrm{Eu}(\mathrm{III})$ contents were compared at a strain rate of $8 \mathrm{~s}^{-1}$. All polymer films had good mechanical strength, and their rupture stresses were nearly independent of the Eu(III) concentration (Figure 4a, Figure S10), which indicated that the introduction of the $\mathrm{Eu}(\mathrm{III})$ monomer into PMA chains did not alter the elastic properties of the films. The total light intensity increased with increasing $\mathrm{Eu}$ (TTA) ${ }_{3}$ (Aphen) acceptor content (Figure 4b). Because from Eu-PMA-1 to Eu-PMA-3, their polymer back bones resemble each other, except for the varied number of side groups that are not effective for mechanical load, it is thus expected that the same number of dioxetane bonds is cleaved overall. Therefore, the increase in the light intensity corresponds to the increased excitation of the $\mathrm{Eu}$ (III) complex to its fluorescent excited state for samples with a higher fraction of the Eu(III) complex. ${ }^{35}$ Second, Eu-PMA-2 films were stretched at different strain rates from 1 to $20 \mathrm{~s}^{-1}$. Because the cumulative light intensity is recognized as being related to the number of dioxetane scissions, the summed intensities of all frames up to a certain time are thus a measure of the total number of broken dioxetane bonds up to that moment. Both the rupture stress and the cumulative light intensity are almost independent of the strain rates (Figure $4 \mathrm{c}, \mathrm{d}$ and Figure S11). At a strain rate of $20 \mathrm{~s}^{-1}$, the recorded light intensity decreased, which was most probably due to the saturation of the camera detector and the time resolution of the camera shutter. ${ }^{36}$ As illustrated in Figure S12, cumulative light at the identical mechanical strain in Eu-PMA-2 is almost independent of strain rates. This is consistent with the fracture mechanism for cross-linked polymers; that is, chain sliding in $\mathrm{Eu}$ (III)-containing cross-linked PMA is largely restricted, and chain breaking plays a leading role in the rupture process.

The advantages of the covalent integration of the $\mathrm{Eu}$ (III) acceptor into the polymer network over the nonbonded counterparts were then revealed. ${ }^{19,37}$ Increasing the mechanoluminescence intensity was previously realized either by physically mixing or by incorporating fluorescent dyes into the polymer main chain. The limitations of the two strategies include either insufficient energy transfer due to the limited solubility of dyes or the interference of mechanical properties if acceptors are in the backbones. Herein, because the Eu(III) complexes are in side chains, increasing the amounts of $\mathrm{Eu}$ (TTA) ${ }_{3}$ (Aphen) (for instance, up to $1.3 \mathrm{wt} \%$ for Eu-PMA3) had little influence on the mechanical properties of the resultant uniform films (Figure 4a), allowing more efficient energy transfer. A control experiment in films with $1.3 \mathrm{wt} \%$ of nonbonded $\mathrm{Eu}(\mathrm{III})$ complex showed distinct signs of aggregation (Figure S13), accompanied by decreased mechanical strength (Figure S14). Optomechanical tests showed more intense mechanoluminescence together with a lowered force threshold for the optical signal from Eu-PMA-3 compared with physically mixed films (Figure S15). Therefore, the covalent anchoring of $\mathrm{Eu}$ (III) acceptors as side groups in a network is very effective to increase the sensitivity of bond scission detection.

Because imaging is of importance when correlating the location of light emission to the actual fracture, next and more importantly, we demonstrated the advance of this methodology in mapping bond breakage during fracture experiments. Remarkably enough, under the same deformation conditions, a 
different number of frames with significant signal intensity was recorded for Eu-PMA-3 (>16 frames) and its physically mixed analogue (eight frames with rather low intensity; Figure 5a and Figure S16a). This result indicates that our strategy can effectively "shift" the appreciable luminescence to the more initial failure stage, which would be helpful for probing more early bond scission events and for the more precise evaluation of the stress-dependent overall scission in rubbery materials that were not previously able to be addressed. Meanwhile, improved spatial resolution was shown with the experiment on the films with a prepunched hole of ca. $600 \mu \mathrm{m}$. As for EuPMA-3, force-induced red light started around the hole, and the bond breakage was very localized at the crack tip, followed by, within milliseconds, propagation over a large region along the extension direction, whereas for the physically mixed film, the spatial evolution of the mechanoluminescence was limited (Figure 5b and Figure S16b). Altogether, these experiments show that our red-emissive dioxetane system can be used to visualize weak points in a polymer before film fracture occurs and the way stresses are distributed around these initial spots. In other words, by combining the sensitized luminescence approach with dioxetane in polymers, without sacrificing the stability of the force probe, more information regarding the spatial and temporal evolution of light can be obtained, which will trigger more microlevel and fundamental studies in the very initial stage of stress distribution and chain scission.

Because these Eu-PMA-Xs are elastic and transparent, with highly increased sensitivity of red mechanoluminescence, we further investigated their application in a stretchable device. The device is a simple bilayer system with a PMA bottom layer that contains carbon black to absorb red light emitting from the upper Eu-PMA-3 layer (Figure S1). The bottom layer is coated with a line pattern of highly reflective $\mathrm{TiO}_{2} / \mathrm{PMA}^{38}$ The strong reflective luminescence from the pattern $\mathrm{TiO}_{2}$ reflector is expected to enhance and localize the mechanoresponsive light, whereas the carbon black part is dark, and thus stretching this device allowed the area having the $\mathrm{TiO}_{2}$ coating to display its corresponding patterns in the dark. As shown in Figure 6, the stripe-like red light was presented upon

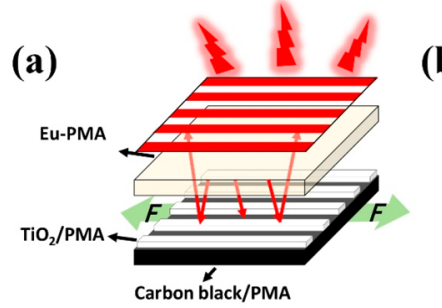

(b)

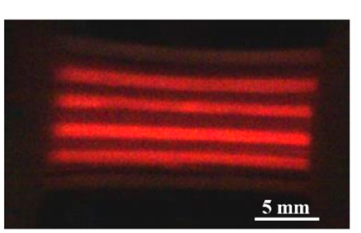

Figure 6. (a) Scheme of the patterned stretchable device. (b) Frame showing the stripe-like red emission upon stretching the bilayer device in the dark.

deforming the device, whereas when coating other reported mechanoluminescent elastomers, ${ }^{19,37}$ because their light intensity was not high enough and tended to be absorbed by the colored films, the patterned light was not detected. These results illustrate that we can prepare smart, sensitive, and deformation-controlled luminescent devices and also highlight the potential applications of these polymers in the failure detection and stress mapping of flexible devices.

\section{CONCLUSIONS}

A new type of mechanochemiluminescent polymers with redlight emitting was accessed through a sensitized luminescence approach. By incorporating the $\left[\mathrm{Eu}(\mathrm{TTA})_{3}(\right.$ Aphen $\left.)\right]$ complex into the side chain of a 1,2-dioxetane cross-linked PMA, $\mathrm{Eu}(\mathrm{III})$ containing mechanoluminescent elastomers was synthesized. The Eu(III) complex turned the blue chemiluminescence from broken dioxetane to a narrow and intense red emission band from the $\mathrm{Eu}(\mathrm{III})$ center and retained the good transparency of the films without affecting their mechanical properties. These factors are critical to improve the resolution of mechanoluminescence and facilitate the in situ study of bond scission. Sensitive bond-breakage mapping in cross-linked elastomers was demonstrated. Moreover, through deformation-controlled surface engineering, optical devices with patterned red mechanoluminescence were fabricated. Our design strategy thus expands the useful space of luminescent stress probes and will contribute to revealing more fundamental questions related to polymer failure.

\section{ASSOCIATED CONTENT}

\section{SI Supporting Information}

The Supporting Information is available free of charge at https://pubs.acs.org/doi/10.1021/acs.macromol.9b02221.

Experimental details, characterization data, more strainstress data, optomechanical data, and additional figures (PDF)

Video S1. Representative video of red mechanochemiluminescence upon stretching an Eu-PMA-2 film (AVI)

Video S2. Representative video of red mechanochemiluminescence upon stretching an Eu-PMA-3 film by hand (AVI)

\section{AUTHOR INFORMATION}

\section{Corresponding Authors}

Rint P. Sijbesma - Institute for Complex Molecular Systems, Eindhoven University of Technology, Eindhoven 5600 MB, Netherlands; 이이.orcid.0000-0002-8975-636X; Email: r.p.sijbesma@tue.nl

Yulan Chen - Tianjin Key Laboratory of Molecular Optoelectronic Science, Department of Chemistry, Tianjin University, Tianjin 300354, P. R. China; Collaborative Innovation Center of Chemical Science and Engineering, Tianjin

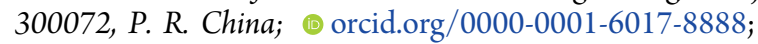
Email: yulan.chen@tju.edu.cn

\section{Authors}

Fan Yang - Tianjin Key Laboratory of Molecular Optoelectronic Science, Department of Chemistry, Tianjin University, Tianjin 300354, P. R. China; Collaborative Innovation Center of Chemical Science and Engineering, Tianjin 300072, P. R. China

Yuan Yuan - Tianjin Key Laboratory of Molecular Optoelectronic Science, Department of Chemistry, Tianjin University, Tianjin 300354, P. R. China; Collaborative Innovation Center of Chemical Science and Engineering, Tianjin 300072, P. R. China

Complete contact information is available at:

https://pubs.acs.org/10.1021/acs.macromol.9b02221

\section{Author Contributions}

${ }$ F.Y. and Y.Y. contributed equally to this work. 


\section{Notes}

The authors declare no competing financial interest.

\section{ACKNOWLEDGMENTS}

We acknowledge financial support by the National Key Research and Development Program of China (grants 2017YFA0204503 and 2017YFA0207800), the National Natural Science Foundation of China (grants 21734006, 21975178, and 21522405), and the Thousand Youth Talents Plan. Prof. Creton Costantino is thanked for helpful discussions.

\section{REFERENCES}

(1) Ni, Y.; Wu, J. Org. Far-red and near infrared BODIPY dyes: synthesis and applications for fluorescent $\mathrm{pH}$ probes and bio-imaging. Org. Biomol. Chem. 2014, 12, 3774-3791.

(2) Qin, W.; Ding, D.; Liu, J.; Yuan, W. Z.; Hu, Y.; Liu, B.; Tang, B. $Z$. Biocompatible nanoparticles with aggregation-Induced emission characteristics as far-red/near-infrared fluorescent bioprobes for in vitro and in vivo imaging applications. Adv. Funct. Mater. 2012, 22, 771-779.

(3) Chen, C.-T. Evolution of red organic light-emitting diodes: materials and devices. Chem. Mater. 2004, 16, 4389-4400.

(4) Hao, J.-N.; Yan, B. Determination of urinary 1-hydroxypyrene for biomonitoring of human exposure to polycyclic aromatic hydrocarbons carcinogens by a lanthanide-functionalized metalorganic framework sensor. Adv. Funct. Mater. 2017, 27, 1603856.

(5) Butler, S. J.; Parker, D. Anion binding in water at lanthanide centres: from structure and selectivity to signalling and sensing. Chem. Soc. Rev. 2013, 42, 1652-1666.

(6) Kumar, R.; Nyk, M.; Ohulchanskyy, T. Y.; Flask, C. A.; Prasad, P. N. Combined optical and MR bioimaging using rare earth ion doped NaYF4 nanocrystals. Adv. Funct. Mater. 2009, 19, 853-859.

(7) Leonard, J. P.; Gunnlaugsson, T. Luminescent $\mathrm{Eu}(\mathrm{III})$ and $\mathrm{Tb}$ (III) complexes: developing lanthanide luminescent-based devices. J. Fluoresc. 2005, 15, 585-595.

(8) Wang, F.; Sun, L. D.; Gu, J.; Wang, Y. F.; Feng, W.; Yang, Y.; Wang, J.; Yan, C. H. Selective Heteroepitaxial Nanocrystal Growth of Rare Earth Fluorides on Sodium Chloride: Synthesis and Density Functional Calculations. Angew. Chem., Int. Ed. 2012, 51, 8796-8799.

(9) Bünzli, J.-C. G.; Wong, K.-L. Lanthanide mechanoluminescence. J. Rare Earths 2018, 36, 1-41.

(10) Feng, A.; Smet, A. P. F. A Review of Mechanoluminescence in Inorganic Solids: Compounds, Mechanisms, Models and Applications. Materials 2018, 11, 484.

(11) Davis, D. A.; Hamilton, A.; Yang, J.; Cremar, L. D.; Van Gough, D.; Potisek, S. L.; Ong, M. T.; Braun, P. V.; Martinez, T. J.; White, S. R.; Moore, J. S.; Sottos, N. R. Force-induced activation of covalent bonds in mechanoresponsive polymeric materials. Nature 2009, 459, $68-72$.

(12) Imato, K.; Irie, A.; Kosuge, T.; Ohishi, T.; Nishihara, M.; Takahara, A.; Otsuka, H. Mechanophores with a reversible radical system and freezing-induced mechanochemistry in polymer solutions and gels. Angew. Chem., Int. Ed. 2015, 54, 6168-6172.

(13) Kim, T. A.; Robb, M. J.; Moore, J. S.; White, S. R.; Sottos, N. R. Mechanical reactivity of two different spiropyran mechanophoresin polydimethylsiloxane. Macromolecules 2018, 51, 9177-9183.

(14) Cho, S.-Y.; Kim, J.-G.; Chung, C.-M. A fluorescent crack sensor based on cyclobutane-containing crosslinked polymers of tricinnamates. Sens. Actuators, B 2008, 134, 822-825.

(15) Song, Y.-K.; Lee, K.-H.; Hong, W.-S.; Cho, S.-Y.; Yu, H.-C.; Chung, C.-M. Fluorescence sensing of microcracks based on cycloreversion of a dimeric anthracene moiety. J. Mater. Chem. 2012, 22, 1380-1386.

(16) Sagara, Y.; Karman, M.; Verde-Sesto, E.; Matsuo, K.; Kim, Y.; Tamaoki, N.; Weder, C. Rotaxanes as mechanochromic fluorescent force transducers in polymers. J. Am. Chem. Soc. 2018, 140, 15841587.
(17) Jia, Y.; Wang, S.; Wang, W.-J.; Li, B.-G.; Zhu, S. Design and synthesis of a well-controlled mechanoluminescentpolymer system based on fluorescence resonance energy transferwith spiropyran as a force-activated acceptor and nitrobenzoxadiazole as a fluorescent donor. Macromolecules 2019, 52, 7920-7928.

(18) Yildiz, D.; Baumann, C.; Mikosch, A.; Kuehne, A. J. C.; Herrmann, A.; Göstl, R. Anti-stokes stress sensing: mechanochemical activation of triplet-triplet annihilation photon upconversion. Angew. Chem., Int. Ed. 2019, 58, 12919-12923.

(19) Chen, Y.; Spiering, A. J.; Karthikeyan, S.; Peters, G. W.; Meijer, E. W.; Sijbesma, R. P. Mechanically induced chemiluminescence from polymers incorporating a 1,2-dioxetane unit in the main chain. Nat. Chem. 2012, 4, 559-562.

(20) Clough, J. M.; Balan, A.; van Daal, T. L.; Sijbesma, R. P. Probing force with mechanobase-induced chemiluminescence. Angew. Chem., Int. Ed. 2016, 55, 1445-1449.

(21) Yuan, Y.; Chen, Y.-1. Visualized bond scission in mechanically activated polymers. Chin. J. Polym. Sci. 2017, 35, 1315-1327.

(22) Clough, J. M.; van der Gucht, J.; Sijbesma, R. P. Mechanoluminescent imaging of osmotic stress-induced damage in a glassy polymer network. Macromolecules 2017, 50, 2043-2053.

(23) Li, J.; Nagamani, C.; Moore, J. S. Polymer mechanochemistry: from destructive to productive. Acc. Chem. Res. 2015, 48, 2181-2190.

(24) Lee, C. K.; Beiermann, B. A.; Silberstein, M. N.; Wang, J.; Moore, J. S.; Sottos, N. R.; Braun, P. V. Exploiting force sensitive spiropyrans as molecular level probes. Macromolecules 2013, 46, $3746-3752$.

(25) Kean, Z. S.; Hawk, J. L.; Lin, S.; Zhao, X.; Sijbesma, R. P.; Craig, S. L. Increasing the maximum achievable strain of a covalent polymer gel through the addition of mechanically invisible cross-links. Adv. Mater. 2014, 26, 6013-6018.

(26) Balkenende, D. W. R.; Coulibaly, S.; Balog, S.; Simon, Y. C.; Fiore, G. L.; Weder, C. Mechanochemistry with metallosupramolecular polymers. J. Am. Chem. Soc. 2014, 136, 10493-10498.

(27) Chen, P.; Li, Q.; Grindy, S.; Holten-Andersen, N. White-lightemitting lanthanide metallogels with tunableluminescence and reversible stimuli-responsive properties. J. Am. Chem. Soc. 2015, $137,11590-11593$.

(28) Clough, J. M.; Sijbesma, R. P. Dioxetane scission products unchanged by mechanical force. ChemPhysChem 2014, 15, 35653571.

(29) Buono-core, G. E.; Li, H.; Marciniak, B. Quenchingofexcitedstatesbylanthanideionsandchelates in solutions. Coord. Chem. Rev. 1990, 99, 55-87.

(30) Xu, C. J.; Li, B. G.; Wan, J. T.; Bu, Z. Y. Synthesis and characterization of a Eu-containing polymer precursor featuring thenoyltrifluoroacetone and 5-acrylamido-1,10-phenanthroline. Spectrochim. Acta, Part A 2011, 82, 159-163.

(31) Xu, C.-J.; Wan, J.-T.; Li, B.-G. Monochromatic light-emitting copolymer of methyl methacrylate and Eu-complexed 5-acrylamido1,10-phenanthroline. Dyes Pigm. 2013, 98, 493-498.

(32) Wang, L.-H.; Wang, W.; Zhang, W.-G.; Kang, E.-T.; Huang, W. Synthesis and luminescence properties of novelEu-containing copolymers consisting of $\mathrm{Eu}(\mathrm{III})$-acrylate- $\beta$-diketonate complex monomers and methyl methacrylate. Chem. Mater. 2000, 12, 22122218.

(33) Vaughan, A. S.; Stevens, G. C. Irradiation and the glass transition in PEEK. Polymer 2001, 42, 8891-8895.

(34) Hummelen, J. C.; Luider, T. M.; Wynberg, H. Functionalized adamantylideneadamantane 1,2-dioxetanes: investigations on stable and inherently chemiluminescent compounds as a tool for clinical analysis. Pure Appl. Chem. 1987, 59, 639-650.

(35) Wildes, P. D.; White, E. H. Dioxetane-sensitized chemiluminescence of lanthanide chelates. A chemical source of "monochromatic" light. J. Am. Chem. Soc. 1971, 93, 6286-6288.

(36) Chen, Y.; Sijbesma, R. P. Dioxetanes as mechanoluminescent probes in thermoplasticelastomers. Macromolecules 2014, 47, 37973805. 
(37) Yuan, W.; Yuan, Y.; Yang, F.; Wu, M.; Chen, Y. Improving mechanoluminescent sensitivity of 1,2-dioxetane containing thermoplastic polyurethanes by controlling energy transfer across polymer chains. Macromolecules 2018, 51, 9019-9025.

(38) Zeng, S.; Zhang, D.; Huang, W.; Wang, Z.; Freire, S. G.; Yu, X.; Smith, A. T.; Huang, E. Y.; Nguon, H.; Sun, L. Bio-inspired sensitive and reversible mechanochromisms via strain-dependent cracks and folds. Nat. Commun. 2016, 7, 11802. 